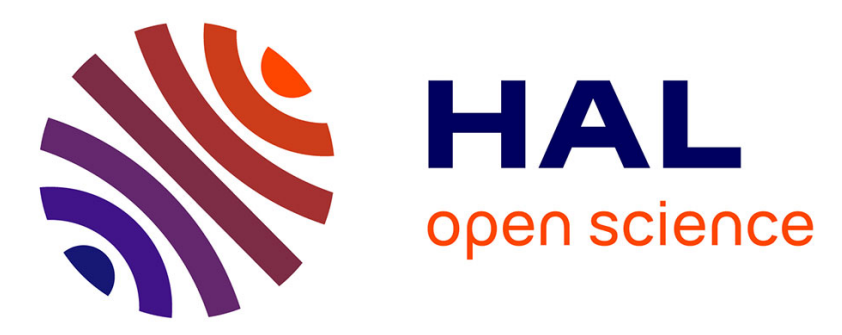

\title{
Diagnosis of Three-Phase Electrical Machines Using Multidimensional Demodulation Techniques
}

Vincent V. Choqueuse, Mohamed Benbouzid, Yassine Amirat, Sylvie Turri

\section{To cite this version:}

Vincent V. Choqueuse, Mohamed Benbouzid, Yassine Amirat, Sylvie Turri. Diagnosis of ThreePhase Electrical Machines Using Multidimensional Demodulation Techniques. IEEE Transactions on Industrial Electronics, 2012, 59 (4), pp.2014-2023. 10.1109/TIE.2011.2160138 . hal-00654230

\section{HAL Id: hal-00654230 \\ https://hal.science/hal-00654230}

Submitted on 21 Dec 2011

HAL is a multi-disciplinary open access archive for the deposit and dissemination of scientific research documents, whether they are published or not. The documents may come from teaching and research institutions in France or abroad, or from public or private research centers.
L'archive ouverte pluridisciplinaire HAL, est destinée au dépôt et à la diffusion de documents scientifiques de niveau recherche, publiés ou non, émanant des établissements d'enseignement et de recherche français ou étrangers, des laboratoires publics ou privés. 


\title{
Diagnosis of Three-Phase Electrical Machines Using Multidimensional Demodulation Techniques
}

\author{
Vincent Choqueuse, Member, IEEE, Mohamed El Hachemi Benbouzid, Senior Member, IEEE, \\ Yassine Amirat, and Sylvie Turri
}

\begin{abstract}
This paper deals with the diagnosis of three-phase electrical machines and focuses on failures that lead to stator-current modulation. To detect a failure, we propose a new method based on stator-current demodulation. By exploiting the configuration of three-phase machines, we demonstrate that the demodulation can be efficiently performed with low-complexity multidimensional transforms such as the Concordia transform (CT) or the principal component analysis (PCA). From a practical point of view, we also prove that PCA-based demodulation is more attractive than CT. After demodulation, we propose two statistical criteria aiming at measuring the failure severity from the demodulated signals. Simulations and experimental results highlight the good performance of the proposed approach for condition monitoring.
\end{abstract}

Index Terms-Condition monitoring, electrical machines, principal component analysis (PCA), signal processing.

\section{INTRODUCTION}

$\mathbf{T}$ HREE-PHASE electrical machines such as induction motors or generators are used in a wide variety of applications. To increase the productivity and to reduce maintenance costs of these systems, condition monitoring and diagnosis are often desired. A wide variety of condition monitoring techniques have been introduced over the last decade. Among them, motor current signature analysis (MCSA) [1] has several advantages since it is usually cheaper and easier to implement than other techniques. In steady-state configurations, MCSA based on stationary spectral analysis techniques is commonly used (fast Fourier transform (FFT) and multiple-signal classification [2]). However, in practice, the steady-state assumption is often violated due to nonconstant-supply-frequency or adjustable-speed drives. In these situations, several authors have investigated the use of nonstationary techniques such as time-frequency representations [1], [3]-[6], time-scale analysis [7]-[10], and polynomial-phase transform [11] (see [12] for a

Manuscript received December 7, 2010; revised April 5, 2011; accepted May 29, 2011. Date of publication June 20, 2011; date of current version November 1, 2011.

V. Choqueuse, M. E. H. Benbouzid, and S. Turri are with the Brest Laboratory of Mechanics and Systems (LBMS), EA 4325, University of Brest, 29238 Brest, France (e-mail: vincent.choqueuse@univ-brest.fr; mohamed. benbouzid@univ-brest.fr; sylvie.turri@univ-brest.fr).

Y. Amirat is with the Brest Laboratory of Mechanics and Systems (LBMS), EA 4325, University of Brest, 29238 Brest, France, and also with the Institut Superieur de l'Electronique et du Numérique, 29228 Brest, France (e-mail: yassine.amirat@univ-brest.fr).

Color versions of one or more of the figures in this paper are available online at http://ieeexplore.ieee.org.

Digital Object Identifier 10.1109/TIE.2011.2160138 more complete review). The main drawback of these methods relies on their computational complexity. Furthermore, these representations usually suffer from poor resolution and/or artifact (cross terms, aliasing, etc.), which can lead to misleading interpretations.

Other investigations on machine modeling have recently demonstrated that many types of failure lead to stator-current modulation with a modulation index which is directly proportional to the failure severity [5], [13]-[17]. In particular, it has been proved that load torque oscillations lead to statorcurrent phase modulation (PM) [9], [13]-[15], whereas air-gap eccentricity and rotor asymmetry lead to stator-current amplitude modulation (AM) [5], [14]. Therefore, a straightforward technique to monitor the behavior of an electrical machine is based on stator-current demodulation.

Classical demodulation techniques include the square-law demodulator, the Hilbert transform (HT) [18], the energy separation algorithm [19], and other approaches. Applications to failure detection are available in [7], [14], and [20]-[27]. Interestingly, for a balanced system, it has been shown in [14], [21], [22], [24], and [28] that the Concordia transform (CT), which has been used for failure detection purposes in [14], [21][24], and [28]-[38], can also be interpreted as a demodulating tool. As compared to classical demodulation tools, CT exhibits interesting properties such as lower complexity and lack of end effect problems or other artifacts [28]. However, in practice, this approach can lead to poor performance since a real machine usually presents a small degree of imbalance [22].

Once the demodulation has been performed, demodulated signals must be further analyzed to measure failure severity. In the literature, many criteria and/or techniques have been proposed to perform this task. In [14], [21], [22], [24], [25], and [29], failure severity is measured through statistical criteria. However, these criteria require knowledge of the fault frequencies, which also depend on other parameters (speed or slip information). To overcome this problem, more sophisticated approaches have been proposed for failure detection. These include neural networks [31], [36], [39], Bayesian classifiers [23], fuzzy logic classifiers [33], [36], genetic algorithms [38], and other classifiers [34]. However, these approaches are computationally demanding, and their performances highly depend on the representativeness of the training set.

In this paper, we address the condition monitoring problem from a signal processing point of view. As failure severity is proportional to the modulation index, we propose to use the modulation-index estimate as a failure severity indicator. The proposed approach is composed of two steps: a stator-current 


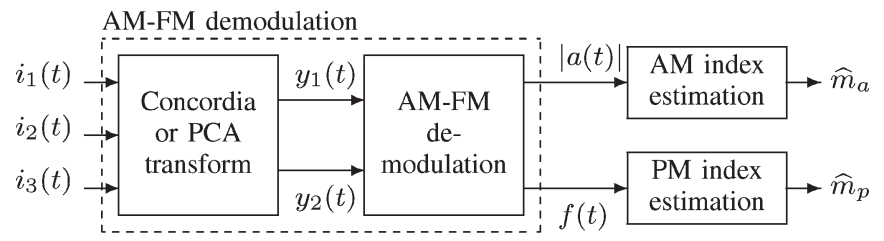

Fig. 1. Block diagram of the proposed technique. Symbols $i_{k}(t)(k=$ $1,2,3)$ correspond to the stator currents, $|a(t)|$ and $f(t)$ correspond to the instantaneous amplitude and frequency, and $\widehat{m}$ corresponds to the modulationindex estimate.

amplitude/frequency demodulation followed by a modulationindex estimation. These steps are described in Fig. 1. To perform demodulation, we propose to exploit the multidimensional nature of three-phase systems through low-complexity linear transforms. Then, we propose to estimate the modulation indexes from the demodulated signals with two original estimators.

This paper is organized as follows. Section II describes the signal model of the stator current under healthy and faulty conditions. Section III investigates the use of CT and principal component analysis (PCA) to perform multidimensional current demodulation, and Section IV describes the proposed failure severity criteria. Finally, Section V reports on the performance of the proposed approach with synthetic and experimental signals.

\section{Signal Model}

In the presence of a fault, it has been shown in [5], [13], [14], and [16] that the stator current is amplitude modulated and/or phase modulated. For AM and/or PM, the instantaneous amplitude $a(t)$ and phase $\phi(t)$ can be expressed respectively as

$$
\begin{aligned}
& a(t)=\alpha\left(1+m_{a} \cos \left(2 \pi f_{a} t\right)\right) \\
& \phi(t)=2 \pi f_{0} t+m_{\phi} \sin \left(2 \pi f_{\phi} t\right)
\end{aligned}
$$

where $\alpha$ is a scaling coefficient, $f_{0}$ is the supply current frequency, and $f_{a}\left(f_{\phi}\right)$ is the $\mathrm{AM}(\mathrm{PM})$ modulating frequency. The scalars $m_{a}$ and $m_{\phi}$ correspond to the AM and PM indexes, respectively. For a faulty system, the modulation indexes are directly proportional to the failure severity. In particular, without any fault, the instantaneous amplitude and frequency do not vary with time, i.e., $m_{a}=m_{\phi}=0$.

Let us consider a three-phase system. In the presence of a fault, all three line currents $i_{1}(t), i_{2}(t)$, and $i_{3}(t)$ are simultaneously modulated, and the currents can be expressed as

$$
\begin{aligned}
& i_{1}(t)=a(t) \cos (\phi(t)) \\
& i_{2}(t)=a(t) \cos (\phi(t)-2 \pi / 3) \\
& i_{3}(t)=a(t) \cos (\phi(t)+2 \pi / 3) .
\end{aligned}
$$

In the literature, most studies assume a perfect balance configuration. However, healthy electrical systems are rarely perfectly balanced. Furthermore, the balance assumption usually does not hold when a failure introduces some asymmetry. In this study, balanced and unbalanced three-phase systems are considered. Let us denote $\mathbf{s}(t)=\left[s_{1}(t), s_{2}(t), s_{3}(t)\right]^{\mathrm{T}}$ the $3 \times$ 1 vector which contains the stator currents, where $(\cdot)^{\mathrm{T}}$ corre- sponds to the matrix transposition. In this paper, we investigate the two following systems.

1) A balanced three-phase system, where the stator currents are given by

$$
\mathbf{s}(t)=\mathbf{i}(t)=\left[i_{1}(t), i_{2}(t), i_{3}(t)\right]^{\mathrm{T}} .
$$

In particular, by using (3), one can easily verify that $s_{1}(t)+s_{2}(t)+s_{3}(t)=0$.

2) A three-phase system with unbalanced currents, where the stator currents are given by

$$
\mathbf{s}(t)=\mathbf{D i}(t)=\left[\alpha_{1} i_{1}(t), \alpha_{2} i_{2}(t), \alpha_{3} i_{3}(t)\right]^{\mathrm{T}}
$$

where $\mathbf{D}$ is a nonscalar $3 \times 3$ diagonal matrix which contains the "nonequal" diagonal entries $\alpha_{1}, \alpha_{2}$, and $\alpha_{3}$. Without loss of generality, ${ }^{1}$ we assume that the overall energy of the system is conserved, i.e., $\sum_{k=1}^{3} \alpha_{k}^{2}=3$.

In this study, the modulation indexes are employed as failure severity indicators. From a signal processing viewpoint, the condition monitoring problem is therefore translated into an estimation problem. One should note that the estimation of the modulation indexes can be simplified by using a demodulation preprocessing step. In the following, the demodulation is performed by using a linear transformation of the stator currents $\mathbf{s}(t)$.

\section{AM/FM Demodulation USING MULTIDIMENSIONAL TRANSFORM}

In this section, we prove that the use of the three-phase current can expedite the demodulation step. In particular, we show that the CT and the PCA can be considered as lowcomplexity techniques for current demodulation. Furthermore, we demonstrate that the PCA has a larger domain of validity than the $\mathrm{CT}$.

\section{A. $C T$}

$\mathrm{CT}$ is a linear transform which converts the three-component $\mathbf{s}(t)$ into a simplified system composed of two components. By denoting $\mathbf{y}^{(c)}(t)=\left[y_{1}^{(c)}(t), y_{2}^{(c)}(t)\right]^{\mathrm{T}}$ the two Concordia components, CT can be expressed into a matrix form as

$$
\mathbf{y}^{(c)}(t)=\left[\begin{array}{l}
y_{1}^{(c)}(t) \\
y_{2}^{(c)}(t)
\end{array}\right]=\sqrt{\frac{2}{3}} \mathbf{C s}(t)
$$

where $\mathbf{C}$ is the $2 \times 3$ Concordia matrix which is equal to

$$
\mathbf{C}=\left[\begin{array}{ccc}
\frac{\sqrt{2}}{\sqrt{3}} & -\frac{1}{\sqrt{6}} & -\frac{1}{\sqrt{6}} \\
0 & \frac{1}{\sqrt{2}} & -\frac{1}{\sqrt{2}}
\end{array}\right] .
$$

One can verify that the Concordia matrix is an orthogonal matrix since it satisfies $\mathbf{C C}^{\mathrm{T}}=\mathbf{I}_{2}$, where $\mathbf{I}_{2}$ is a $2 \times 2$ identity matrix.

\footnotetext{
${ }^{1}$ One should note that the overall energy can be absorbed into the coefficient
} $\alpha$ in (1). 
By using (3), (4), and (6), it can be demonstrated that the Concordia components of a balanced system are equal to

$$
\begin{aligned}
& y_{1}^{(c)}(t)=a(t) \cos (\phi(t)) a \\
& y_{2}^{(c)}(t)=a(t) \sin (\phi(t)) a .
\end{aligned}
$$

These components $y_{1}^{(c)}(t)$ and $y_{2}^{(c)}(t)$ are called in-phase and quadrature components in the signal processing community.

Let us define the complex signal $z^{(c)}(t)$ as

$$
z^{(c)}(t)=y_{1}^{(c)}(t)+j y_{2}^{(c)}(t) .
$$

By using (8) and (9), one can verify that $z^{(c)}(t)$ is the analytical signal of $s_{1}(t)$, i.e., $z^{(c)}(t)=a(t) e^{j \phi(t)}$. Therefore, the instantaneous amplitude and frequency can be obtained from the modulus and the derivative of the argument of $z^{(c)}(t)$, respectively, i.e.,

$$
\begin{aligned}
& a(t)=\left|z^{(c)}(t)\right| \\
& f(t)=\frac{1}{2 \pi} \frac{d \arg \left[z^{(c)}(t)\right]}{d t}
\end{aligned}
$$

where $|\cdot|$ and $\arg [\cdot]$ correspond to the modulus and the argument, respectively. It is important to note that (10) only holds for a balanced system, i.e., for $\mathbf{s}(t)=\mathbf{i}(t)$.

\section{B. $P C A$}

PCA is a statistical tool that transforms a number of correlated signals into a smaller number of principal components. In [40], PCA is employed after a CT to detect a failure; however, no mathematical analysis has been performed to give a physical interpretation to the principal components. In [41], the PCA is applied on the three-phase stator currents directly, but only two principal components are extracted, without any mathematical justification. In this section, we give a deep theoretical analysis of PCA for balanced and (static) unbalanced three-phase systems. We show why the PCA can be applied on the statorcurrent signals directly. Furthermore, we demonstrate why the PCA can only extract two principal components and why principal components are strongly linked to in-phase and quadrature components. Finally, as opposed to CT, we prove that the PCA can be employed for signal demodulation whatever the balance assumption.

Let us define the $3 \times 3$ covariance matrix as

$$
\mathbf{R}_{s}=E\left[\mathbf{s}(t) \mathbf{s}^{\mathrm{T}}(t)\right]
$$

where $E[\cdot]$ denotes the mathematical expectation. Using (3), one can remark that $i_{3}(t)=-i_{1}(t)-i_{2}(t)$. Therefore, each component of $\mathbf{s}(t)$ can be rewritten as a linear combination of the two components $i_{1}(t)$ and $i_{2}(t)$ whatever the balance assumption. ${ }^{2}$ Using an eigenvalue decomposition, it follows that the $3 \times 3$ symmetric matrix $\mathbf{R}_{x}$ contains one zero eigenvalue. Therefore, $\mathbf{R}_{x}$ can be decomposed under the following form:

$$
\mathbf{R}_{s}=\mathbf{U} \Lambda \mathbf{U}^{\mathrm{T}}
$$

${ }^{2}$ For unbalanced systems, one can verify that $s_{1}(t)=\alpha_{1} i_{1}(t), s_{2}(t)=$ $\alpha_{2} i_{2}(t)$, and $s_{3}(t)=-\alpha_{3}\left(i_{1}(t)+i_{2}(t)\right)$. where $\mathbf{U}$ is a $3 \times 2$ orthogonal matrix $\left(\mathbf{U}^{\mathrm{T}} \mathbf{U}=\mathbf{I}_{2}\right)$ containing the two eigenvectors and $\Lambda=\operatorname{diag}\left(\lambda_{1}, \lambda_{2}\right)$ is a diagonal matrix containing the two nonzero associated eigenvalues $\lambda_{1}$ and $\lambda_{2}$. The two principal components of $\mathbf{s}(t)$, denoted $\mathbf{y}^{(p)}(t)=$ $\left[y_{1}^{(p)}(t), y_{2}^{(p)}(t)\right]^{\mathrm{T}}$, are given by

$$
\mathbf{y}^{(p)}(t)=\left[\begin{array}{l}
y_{1}^{(p)}(t) \\
y_{2}^{(p)}(t)
\end{array}\right]=\beta_{s} \Lambda^{-\frac{1}{2}} \mathbf{U}^{\mathrm{T}} \mathbf{s}(t)
$$

where $\beta_{s}$ is a scaling term which is equal to

$$
\beta_{s}=\sqrt{\frac{\operatorname{trace}\left[\mathbf{R}_{s}\right]}{3}}
$$

with trace $[\cdot]$ being the sum of the diagonal elements. Using (12) and (13), one can verify that the PCA components are uncorrelated.

Under the assumptions that $\phi(t)$ is uniformly distributed in $\left[02 \pi\left[{ }^{3}\right.\right.$ and that $a(t)$ and $\phi(t)$ are independent, it is demonstrated in the Appendix that the PCA components are equal to

$$
\begin{aligned}
& y_{1}^{(p)}(t)=a(t) \cos (\phi(t)-\theta) \\
& y_{2}^{(p)}(t)=a(t) \sin (\phi(t)-\theta)
\end{aligned}
$$

where $\theta \in \mathbb{Z}$ whatever the balance assumption.

Let us define the complex signal $z^{(p)}(t)$ as

$$
z^{(p)}(t)=y_{1}^{(p)}(t)+j y_{2}^{(p)}(t) .
$$

By using (15) and (16), one can verify that $z^{(p)}(t)$ is a rotated version of the analytical signal of $s_{1}(t)$, i.e., $z^{(p)}(t)=$ $a(t) e^{j \phi(t)-\theta}$. Therefore, the instantaneous amplitude and frequency can be obtained from the modulus and the derivative of the argument of $z^{(p)}(t)$, respectively, i.e.,

$$
\begin{aligned}
& a(t)=\left|z^{(p)}(t)\right| \\
& f(t)=\frac{1}{2 \pi} \frac{d \arg \left[z^{(p)}(t)\right]}{d t} .
\end{aligned}
$$

As opposed to (10), it is interesting to note that (17) holds whatever the balance assumption. Therefore, the PCA-based demodulation is less restrictive than the Concordia one.

\section{Modulation-Index Estimation}

After demodulation, the analytical signal and the instantaneous amplitude and/or frequency must be properly analyzed to assess failure severity. Many papers propose to monitor the deviation of the analytical signal $z(t)$ from a circle in the complex plane [29]-[32], [34]-[37], [40]. This solution is perfectly valid if the failure leads to stator-current AM since the radius $|a(t)|$ varies with time. However, if the failure leads to PM, this solution is no longer correct since the failure only affects the rotational speed in the complex plane. In this section, we propose to estimate the AM and PM indexes to assess the failure severity. Using the demodulated signals, two original estimators

\footnotetext{
${ }^{3}$ From a decision viewpoint, the uniform probability density function (pdf) for the phase represents the most ignorance that can be exhibited by the fault detector. This is called the least favorable pdf for $\phi(t)$ [42].
} 
of the modulation indexes are provided. These estimators are based on the method-of-moments (MoM) technique. Although the MoM estimation technique has no optimal properties, it produces an estimator that is easy to determine and simple to implement [43].

\section{A. Estimation of $m_{a}$}

Let us consider the AM signal model in (1). Under the assumption that $2 \pi f_{a} t(\bmod 2 \pi)$ is uniformly distributed in [0 $2 \pi$ [, it is demonstrated in the Appendix that the variance of the instantaneous amplitude is given by

$$
\sigma_{a}^{2}=E\left[\left(a(t)-\mu_{a}\right)^{2}\right]=\frac{\mu_{a}^{2} m_{a}^{2}}{2}
$$

where $\mu_{a}=E[a(t)]$ is the statistical average of $f(t)$. Therefore

$$
m_{a}=\frac{\sigma_{a} \sqrt{2}}{\mu_{a}} .
$$

The corresponding MoM estimator, denoted $\widehat{m}_{a}$, is obtained by replacing the theoretical moments $\mu_{a}$ and $\sigma_{a}$ by their natural estimators.

\section{B. Estimation of $m_{\phi}$}

Let us consider the PM signal model in (2). Taking the derivative of $\phi(t)$ leads to the instantaneous frequency, which is equal to

$$
f(t)=\frac{1}{2 \pi} \frac{d \phi(t)}{d t}=f_{0}+m_{\phi} f_{\phi} \cos \left(2 \pi f_{\phi} t\right) .
$$

Under the assumption that $2 \pi f_{\phi} t(\bmod 2 \pi)$ is uniformly distributed in $[02 \pi$, it can be demonstrated that the variance of the instantaneous frequency is (see the Appendix for a similar proof)

$$
\sigma_{f}^{2}=E\left[\left(f(t)-\mu_{f}\right)^{2}\right]=\frac{m_{\phi}^{2} f_{\phi}^{2}}{2}
$$

where $\mu_{f}=E[f(t)]$ is the statistical average of $f(t)$. Therefore

$$
m_{\phi}=\frac{\sigma_{f} \sqrt{2}}{f_{\phi}} .
$$

The corresponding MoM estimator $\widehat{m}_{\phi}$ is obtained by replacing the theoretical moments by their natural estimators. One should note that the criterion $m_{\phi}$ depends on the modulating frequency $f_{\phi}$. If this frequency is unknown, it can be replaced by its estimate $\widehat{f}_{\phi}$. This estimate can be obtained, for example, by maximizing the periodogram of $f(t)$ [44], [45].

\section{Performances}

This section reports on the performances of the proposed approaches. Experiments were performed with a supply frequency equal to $f_{0}=50 \mathrm{~Hz}$. Signals were sampled with a sampling period of $T_{s}=10^{-4} \mathrm{~s}$, and the proposed technique was applied offline in Matlab. For discrete signals, a straightforward adaptation of the proposed techniques is given by Algorithms 1 and 2, respectively. As compared to the continuous case, $\mathbf{s}(t)$ is replaced by its discrete counterpart $\mathbf{s}[n]=\mathbf{s}\left(n T_{s}\right)$, where $T_{s}$ is the sampling period and $n=0,1, \ldots, N-1$. Furthermore, the instantaneous frequency is approximated by replacing the phase derivative with a two-sample difference, ${ }^{4}$ and the statistical moments are replaced by their natural estimators. In particular, $f(n), \mathbf{R}_{s}, m_{a}, m_{f}, \sigma_{a}^{2}$, and $\sigma_{f}^{2}$ are respectively given by

$$
\begin{aligned}
f(n) & =\frac{\arg [z(n)]-\arg [z(n-1)]}{2 \pi T_{s}} \\
\widehat{\mathbf{R}}_{s} & =\frac{1}{N} \sum_{n=0}^{N-1} \mathbf{s}[n] \mathbf{s}^{\mathrm{T}}[n] \\
\widehat{\mu}_{a} & =\frac{1}{N} \sum_{n=0}^{N-1} a[n] \\
\widehat{\mu}_{f} & =\frac{1}{N} \sum_{n=0}^{N-1} f[n] \\
\widehat{\sigma}_{a}^{2} & =\frac{1}{N} \sum_{n=0}^{N-1}\left(a[n]-\widehat{\mu}_{a}\right)^{2} \\
\widehat{\sigma}_{f}^{2} & =\frac{1}{N} \sum_{n=0}^{N-1}\left(f[n]-\widehat{\mu}_{f}\right)^{2} .
\end{aligned}
$$

The next sections present the performances of the proposed algorithms with synthetic and experimental signals, respectively.

\section{Algorithm 1 Concordia-based failure severity criteria}

1) Extract $N$-data samples $\mathbf{s}[n]$.

2) Compute $\mathbf{y}^{(c)}[n]$ with (6).

3) Compute the analytical signal $z^{(c)}[n]$ with (9).

4) Extract the AM demodulated signal $a[n]$ with (10a).

5) Extract the FM demodulated signal $f[n]$ with (23).

6) Compute $\widehat{m}_{a}$ with (19), (25), and (27).

7) Compute $\widehat{m}_{\phi}$ with (22), (26), and (28).
1) Extract $N$-data samples $\mathbf{s}[n]$.
2) Compute $\mathbf{R}_{s}$ with (24).
3) Perform eigenvalue decomposition of $\mathbf{R}_{s}$ as in (12).
4) Compute $\beta_{s}$ with (14).
5) Compute $\mathbf{y}^{(p)}[n]$ with (13).
6) Compute the analytical signal $z^{(p)}[n]$ with (16).
7) Extract the AM demodulated signal $a[n]$ with (17a).
8) Extract the FM demodulated signal $f[n]$ with (23).
9) Compute $\widehat{m}_{a}$ with (19), (25), and (27).
10) Compute $\widehat{m}_{\phi}$ with (22), (26), and (28).

\section{A. Synthetic Signals}

Synthetic signals $\mathbf{s}(n)$ were simulated by using the signal model in (3). Analysis of the algorithm performances with amplitudeand phase-modulated signals is investigated independently.

\footnotetext{
${ }^{4}$ Before subtraction, a phase unwrapping operation must be applied to avoid phase jumps between consecutive elements.
} 

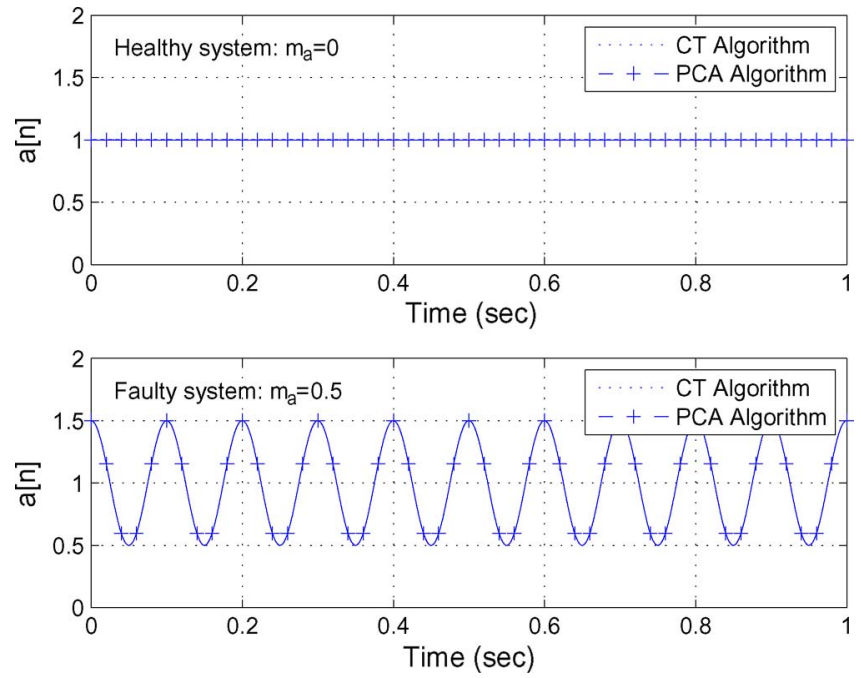

Fig. 2. AM demodulated signals for a healthy $\left(m_{a}=0\right)$ and a faulty $\left(m_{a}=\right.$ $0.5)$ balanced system.
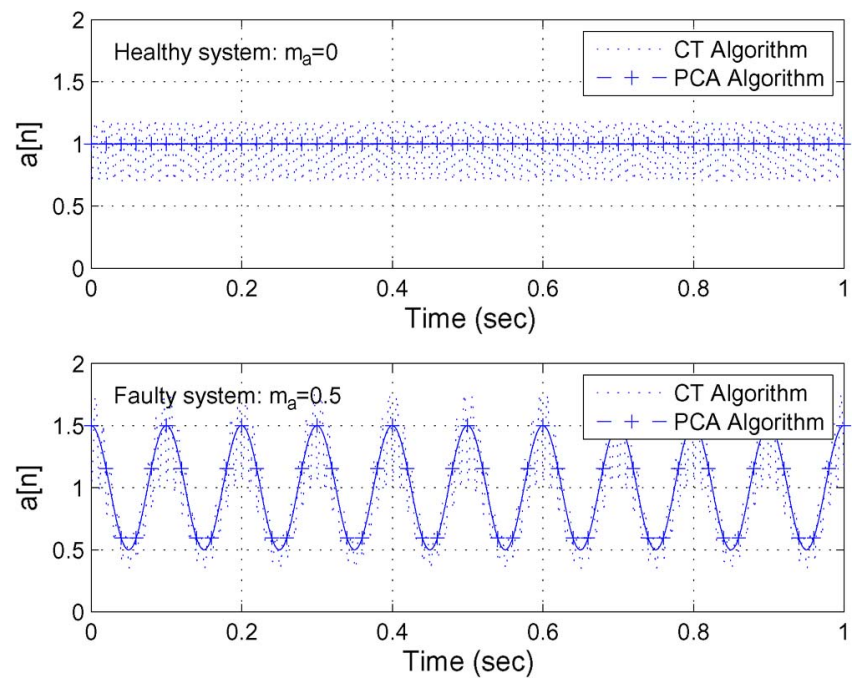

Fig. 3. AM demodulated signals for a healthy $\left(m_{a}=0\right)$ and a faulty $\left(m_{a}=\right.$ $0.5)$ unbalanced system.

1) $A M$ : Let us consider a discrete AM signal $a[n]$ with a modulating frequency equal to $f_{a}=10 \mathrm{~Hz}$, i.e.,

$$
a[n]=1+m_{a} \cos \left(20 \pi n T_{s}\right)
$$

where $m_{a}$ is the modulation index. Figs. 2 and 3 show the demodulated signal $\widehat{a}[n]$ obtained with the Concordia and the PCA transform for balanced $\left(\alpha_{k}=1\right)$ and unbalanced systems $\left(\alpha_{1}=1.323, \alpha_{2}=0.5\right.$, and $\left.\alpha_{3}=1\right)$, respectively. Demodulated signals are displayed for $m_{a}=0$ and $m_{a}=0.5$. In Fig. 2, one can note that both algorithms perform well since demodulation is near perfect. However, for the unbalanced system, PCA clearly outperforms CT since the latter exhibits interference terms which can lead to misleading interpretations. Table I presents the values of $\widehat{m}_{a}, \widehat{m}_{\phi}$, and $\gamma$ for $m_{a}=0$ and $m_{a}=0.5$. As expected, one could observe that the CT-based algorithm leads to a perfect modulation-index estimate for the balanced system ( $\widehat{m}_{a}=m_{a}$ and $\left.\widehat{m}_{f}=0\right)$ but leads to incorrect results for the unbalanced case $\left(\widehat{m}_{a} \neq m_{a}\right.$ and $\left.\widehat{m}_{\phi} \neq 0\right)$. As opposed to the CT algorithm, the PCA algorithm leads to a perfect estimation whatever the balance assumption.
TABLE I

FAULTY SySTEM LEADING TO STATOR-CURRENT AM.

FAILURE SEVERITY CRITERIA $\widehat{m}_{a}$ AND $\widehat{m}_{\phi}$ FOR

HeAlthy $\left(m_{a}=0\right)$ AND FAULTy $\left(m_{a}=0.5\right)$ SYSTEMS

\begin{tabular}{|c|c|c||c|c||c|c|}
\hline \multirow{2}{*}{ System } & \multicolumn{2}{|c||}{$\begin{array}{c}\text { Modulation } \\
\text { Index }\end{array}$} & \multicolumn{2}{c||}{$\begin{array}{c}\text { Algorithm 1 } \\
\text { Concordia }\end{array}$} & \multicolumn{2}{c|}{$\begin{array}{c}\text { Algorithm 2 } \\
\text { PCA }\end{array}$} \\
\cline { 2 - 7 } & $m_{a}$ & $m_{\phi}$ & $\widehat{m}_{a}$ & $\widehat{m}_{\phi}$ & $\widehat{m}_{a}$ & $\widehat{m}_{\phi}$ \\
\hline \multirow{2}{*}{ Balanced } & 0.0 & 0.0 & 0.0 & 0.0 & 0.0 & 0.0 \\
& 0.5 & 0.0 & 0.5 & 0.0 & 0.5 & 0.0 \\
\hline \multirow{2}{*}{ Unbalanced } & 0.0 & 0.0 & 0.24 & 0.26 & 0.0 & 0.0 \\
& 0.5 & 0.0 & 0.56 & 0.26 & 0.5 & 0.0 \\
\hline
\end{tabular}
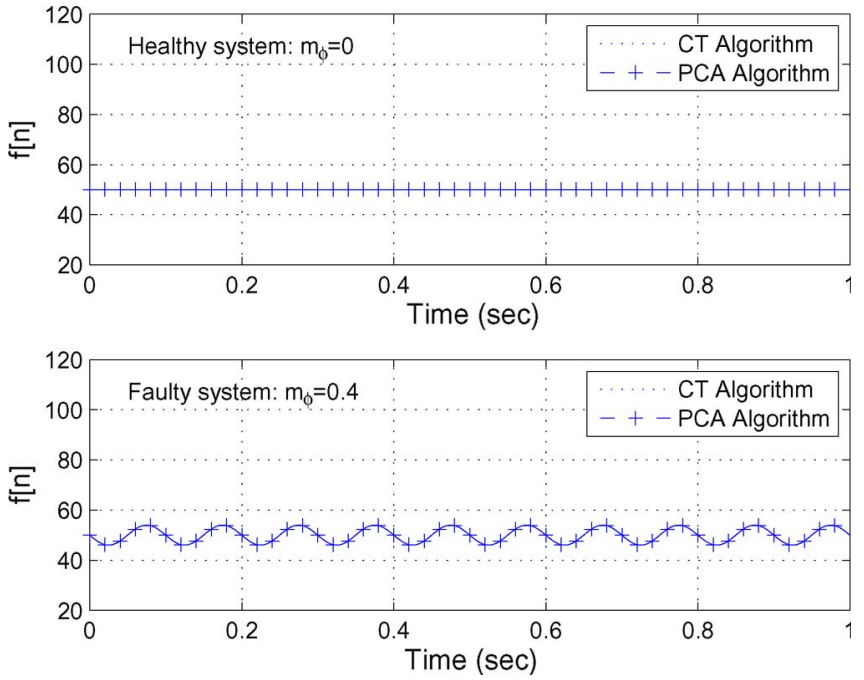

Fig. 4. FM demodulated signals for a healthy $\left(m_{\phi}=0\right)$ and a faulty $\left(m_{\phi}=\right.$ 0.4 ) balanced system.
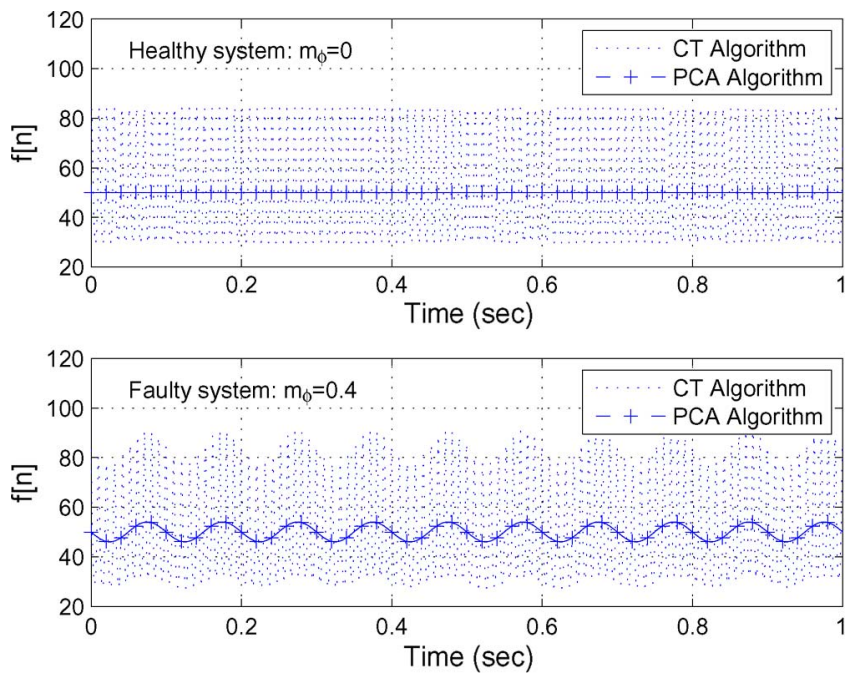

Fig. 5. FM demodulated signals for a healthy $\left(m_{\phi}=0\right)$ and a faulty $\left(m_{\phi}=\right.$ $0.4)$ unbalanced system.

2) PM: Let us consider a discrete PM signal $\phi[n]$, with a modulating frequency equal to $10 \mathrm{~Hz}$, i.e.,

$$
\phi[n]=2 \pi f_{0} n T_{s}+m_{\phi} \sin \left(20 \pi n T_{s}\right)
$$

where $m_{\phi}$ is the modulation index. Figs. 4 and 5 show the instantaneous frequency $f[n]$ extracted with the Concordia and the PCA transform for healthy $\left(m_{\phi}=0\right)$ and faulty $\left(m_{\phi}=0.4\right)$ systems. As expected, PCA-based demodulation clearly outperforms the CT-based one since it gives perfect 
TABLE II

FAULTY SYSTEM LEADING TO STATOR-CURRENT PM. FAILURE SEVERITY CRITERIA $\widehat{m}_{a}$ AND $\widehat{m}_{\phi}$ FOR HEALThy $\left(m_{\phi}=0\right)$ AND FAULTy $\left(m_{\phi}=0.4\right)$ Systems

\begin{tabular}{|c|c|c||c|c||c|c|}
\hline \multirow{2}{*}{ System } & \multicolumn{2}{|c||}{$\begin{array}{c}\text { Modulation } \\
\text { Index }\end{array}$} & \multicolumn{2}{c||}{$\begin{array}{c}\text { Algorithm 1 } \\
\text { Concordia }\end{array}$} & \multicolumn{2}{c|}{$\begin{array}{c}\text { Algorithm 2 } \\
\text { PCA }\end{array}$} \\
\cline { 2 - 7 } & $m_{a}$ & $m_{\phi}$ & $\widehat{m}_{a}$ & $\widehat{m}_{\phi}$ & $\widehat{m}_{a}$ & $\widehat{m}_{\phi}$ \\
\hline \multirow{2}{*}{ Balanced } & 0.0 & 0.0 & 0.0 & 0.0 & 0.0 & 0.0 \\
& 0.0 & 0.4 & 0.0 & 0.4 & 0.0 & 0.4 \\
\hline \multirow{2}{*}{ Unbalanced } & 0.0 & 0.0 & 0.24 & 13.1 & 0.0 & 0.0 \\
& 0.0 & 0.4 & 0.24 & 13.1 & 0.0 & 0.4 \\
\hline
\end{tabular}

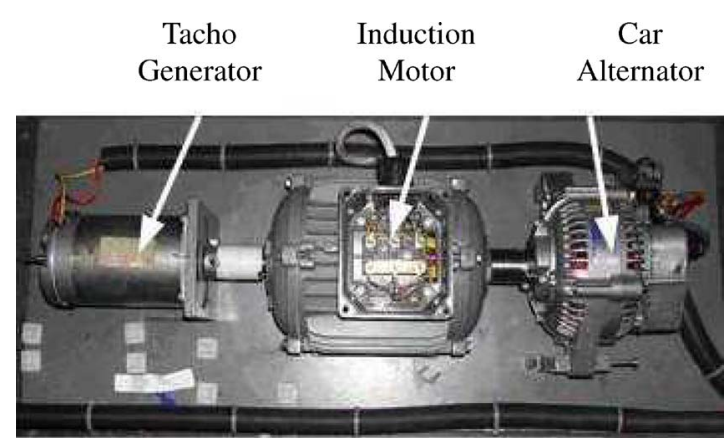

Fig. 6. Mechanical part of the experimental setup. Faulty machines are simulated with artificially deteriorated bearings [36]

demodulation whatever the amount of current imbalance. Table II presents the values of the modulation-index estimates. For the balanced system, one can observe that the two techniques give perfect results since $\widehat{m}_{\phi}=0.4$. However, for the unbalanced case, Table II shows that the CT-based approach leads to incorrect results and makes the fault detection more difficult.

\section{B. Experimental Signals}

The experimental setup is composed of a tachogenerator, a three-phase squirrel-cage induction motor, and a car alternator (see Fig. 6). The parameters of the induction motor are as follows: $0.75 \mathrm{~kW}, 220 / 380 \mathrm{~V}, 1.95 / 3.4 \mathrm{~A}, 2780 \mathrm{r} / \mathrm{min}, 50 \mathrm{~Hz}$, and two poles. The tested motor has two 6204.2ZR-type bearings. The outside bearing diameter is $47 \mathrm{~mm}$, and the inside one is $20 \mathrm{~mm}$. Assuming the same thickness for the inner and the outer races leads to a pitch diameter equal to $D_{P}=31.85 \mathrm{~mm}$. The bearing has eight balls $(N=8)$ with a diameter equal to $D_{B}=12 \mathrm{~mm}$. The experimental tests have been performed with healthy and faulty bearings (inner race deterioration) under different motor load conditions [36].

As the faulty bearing introduces PM [15], the instantaneous frequency contains most of the information about the fault. Fig. 7 shows $f[n]$ for healthy and faulty machines at a $300-\mathrm{W}$ load condition. Additional processings show that the fault frequency is equal to $f_{\phi}=300 \mathrm{~Hz}$ whatever the load condition. Table III presents the values of the proposed criteria $\widehat{m}_{a}$ and $\widehat{m}_{f}$ when the motor operates under different motor load conditions. From Table III, one can observe that the faulty bearings both increase $\widehat{m}_{a}$ and $\widehat{m}_{\phi}$. One can also note that $\widehat{m}_{a} \neq 0$ for the healthy and faulty bearings. Indeed, signal $\mathbf{s}[n]$ is not perfectly sinusoidal and is composed of a small amount of AM even for the healthy bearing.

Comparing Algorithms 1 and 2, one can easily verify that the PCA-based criteria outperform the Concordia-based ones
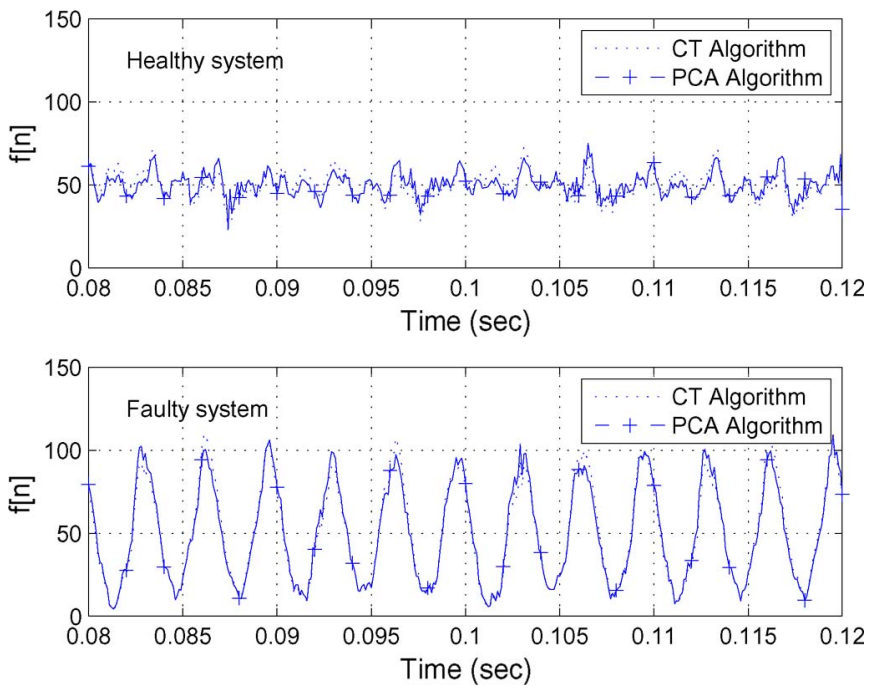

Fig. 7. FM demodulated signals for the healthy and faulty machines (bearing fault) with 300-W load.

TABLE III

EXPERIMENTAl Results With THE HEALThy AND FAulty BeARings. DEMOdUlation USING THE CONCORDIA OR THE PCA TRANSFORM

\begin{tabular}{|c|c||c|c||c|c|}
\hline \multirow{2}{*}{ Load } & \multirow{2}{*}{\multicolumn{1}{|c||}{ Bearing }} & \multicolumn{2}{c||}{$\begin{array}{c}\text { Algorithm 1 } \\
\text { Concordia }\end{array}$} & \multicolumn{2}{c|}{$\begin{array}{c}\text { Algorithm } 2 \\
\text { PCA }\end{array}$} \\
\cline { 3 - 6 } & & $\widehat{m}_{a}$ & $\widehat{m}_{\phi}$ & $\widehat{m}_{a}$ & $\widehat{m}_{\phi}$ \\
\hline \multirow{3}{*}{ No Load } & Healthy & 0.17 & 0.076 & 0.15 & 0.071 \\
& Faulty & 0.24 & 0.196 & 0.23 & 0.193 \\
\cline { 2 - 6 } & Variation & $+38 \%$ & $+158 \%$ & $+49 \%$ & $+170 \%$ \\
\hline \multirow{3}{*}{ 100W } & Healthy & 0.18 & 0.063 & 0.16 & 0.054 \\
& Faulty & 0.22 & 0.183 & 0.21 & 0.181 \\
\cline { 2 - 6 } & Variation & $+26 \%$ & $+192 \%$ & $+30 \%$ & $+230 \%$ \\
\hline \multirow{3}{*}{$300 \mathrm{~W}$} & Healthy & 0.14 & 0.043 & 0.12 & 0.037 \\
& Faulty & 0.20 & 0.166 & 0.19 & 0.164 \\
\cline { 2 - 6 } & Variation & $+38 \%$ & $+286 \%$ & $+52 \%$ & $+340 \%$ \\
\hline & Healthy & 0.12 & 0.038 & 0.10 & 0.034 \\
& Faulty & 0.16 & 0.141 & 0.16 & 0.140 \\
\cline { 2 - 6 } & Variation & $+38 \%$ & $+263 \%$ & $+53 \%$ & $+316 \%$ \\
\hline
\end{tabular}

whatever the motor load. Indeed, in all experiments, healthy and faulty bearings are easier to distinguish with the PCA-based criteria. In particular, at a $200-\mathrm{W}$ load motor condition, a faulty bearing leads to an increase in $\widehat{m}_{\phi}$ of $286 \%$ for Algorithm 1 and $340 \%$ for Algorithm 2. These results come from the fact that experimental signals contain a small amount of current imbalance, which makes PCA better suited than CT for current demodulation.

To compare the proposed approach with a conventional demodulation technique, Table IV presents the values of $\widehat{m}_{a}$ and $\widehat{m}_{\phi}$ obtained with an HT. The comparison of Table IV with Table III shows that the bearing fault is easier to detect with the criterion $\widehat{m}_{\phi}$ presented in Table III. Therefore, in our context, the multidimensional demodulation techniques seem to be better suited than the conventional HT. The differences can be explained by the intrinsic limitations of the HT: First, the domain of validity of this transform is restricted by the Bedrosian theorem [28]; then, the instantaneous amplitude and frequency obtained with HT can present overshoots at both ends [26]. Another advantage of the CT and PCA techniques over HT lies in the computational complexity. CT and PCA are linear transforms; therefore, they are simpler to implement than HT, which involves FFT and inverse FFT computations. 
TABLE IV

EXPERIMENTAL RESUlts With HEALTHy AND FaUlty Bearings. Demodulation Using HT

\begin{tabular}{|c|c||c|c|}
\hline \multirow{2}{*}{ Load } & \multirow{2}{*}{\multicolumn{1}{|c||}{ Bearing }} & \multicolumn{2}{c|}{$\begin{array}{c}\text { Hilbert-based } \\
\text { demodulation }\end{array}$} \\
\cline { 3 - 4 } & & $\widehat{m}_{a}$ & $\widehat{m}_{\phi}$ \\
\hline \multirow{3}{*}{ No Load } & Healthy & 0.120 & 0.100 \\
& Faulty & 0.198 & 0.135 \\
\cline { 2 - 4 } & Variation & $+64 \%$ & $+34 \%$ \\
\hline \multirow{3}{*}{$100 \mathrm{~W}$} & Healthy & 0.128 & 0.093 \\
& Faulty & 0.196 & 0.132 \\
\cline { 2 - 4 } & Variation & $+52 \%$ & $+42 \%$ \\
\hline \multirow{3}{*}{$200 \mathrm{~W}$} & Healthy & 0.096 & 0.078 \\
& Faulty & 0.173 & 0.119 \\
\cline { 2 - 4 } & Variation & $+79 \%$ & $+51 \%$ \\
\hline \multirow{3}{*}{$300 \mathrm{~W}$} & Healthy & 0.082 & 0.070 \\
& Faulty & 0.148 & 0.102 \\
\cline { 2 - 4 } & Variation & $+79 \%$ & $+45 \%$ \\
\hline
\end{tabular}

\section{DISCUSSION}

A standard approach for signal demodulation is based on the extraction of the analytical signal. An analytical signal is usually extracted from the HT for a monodimensional signal. In the case of balanced three-phase systems, the previous sections have shown that the analytical signal can be efficiently extracted with the CT or PCA. These transformations have several advantages over HT: First, they are simpler to implement; then, they are free from signal artifacts (overshoots).

The main drawback of CT relies on its domain of validity. Indeed, for an unbalanced system, this transform cannot be employed for current demodulation. On the contrary, the PCA transform, which is a data-driven approach, is well suited for an unbalanced system. Another interesting property of PCA relies on the fact that it can easily measure the amount of static imbalance. Indeed, (40) shows that the eigenvalues of $\mathbf{R}_{s}$ are equal for balanced systems, i.e., $\lambda_{1}=\lambda_{2}$. For unbalanced systems, this property does not hold, and $\lambda_{1} \neq \lambda_{2}$. Therefore, an equality test can be employed to distinguish between balanced and unbalanced systems. This strategy has been previously employed to detect stator winding faults in [41], and an ad hoc criterion has been proposed to perform the equality test. Interestingly, this equality test is well known in the signal processing community and refers to a "sphericity test" [46].

In the field of multidimensional signal processing, another popular technique is the independent component analysis (ICA) [47]. Whereas PCA focuses on correlation (i.e., second-order statistics), the ICA focuses on statistical independence, a stronger property, which is usually measured through higher order statistics. Therefore, it can be tempting to use ICA to improve the performance of the proposed method. However, in our study, it can be proved that the ICA is useless. Indeed, most of the ICA algorithms are composed of two steps: a PCA preprocessing step followed by a demixing step. After the PCA, the demixing step searches for an orthogonal matrix that maximizes the statistical independence of the PCA components. Nevertheless, in our context, ${ }^{5}$ multiplying $\mathbf{y}^{p}(t)$ with a $2 \times 2$ orthogonal matrix only modifies the value of $\theta$ in (15). As $\theta$ does not affect $a[n]$ and $f[n]$, the demixing step is useless, and the algorithm can therefore be limited to a PCA transform for demodulation.

\section{CONCLUSION}

This paper has focused on condition monitoring of threephase electrical systems. A new method based on the amplitude and phase demodulation of the three-phase stator current with linear transforms has been proposed. The performances of two linear transforms have been investigated: the CT and the PCA. Based on a deep theoretical analysis, it has been proved that the PCA has a larger domain of validity than CT since it can deal with unbalanced currents.

Then, two original criteria have been described to assess the failure severity from the demodulated current. The performances of the proposed criteria have been corroborated by means of simulations with synthetic and experimental signals. In particular, the results have shown that the PCA-based demodulation outperforms the Concordia-based one since it can be employed for unbalanced stator currents.

\section{APPENDIX}

Let us compute the correlation matrix $\mathbf{R}_{i}=E\left[\mathbf{i}(t) \mathbf{i}^{\mathrm{T}}(t)\right]$ for a balanced system. Using (3) and under the assumption that $a(t)$ and $\phi(t)$ are independent variables, one gets for all $u=1,2,3$ and $v=1,2,3$

$$
E\left[i_{u}(t) i_{v}(t)\right]=E\left[a^{2}(t)\right] E_{u v}
$$

where

$$
E_{u v}=E\left[\cos \left(\phi(t)+\psi_{u}\right) \cos \left(\phi(t)+\psi_{v}\right)\right]
$$

with $\psi_{1}=0, \psi_{2}=-2 \pi / 3$, and $\psi_{3}=2 \pi / 3$. Let us assume that the random variable $x=\phi(t)$ is distributed in $[0,2 \pi[$ according to a uniform pdf, i.e., $f(x)=1 / 2 \pi$ if $x \in[0,2 \pi[$ and $f(x)=0$ if elsewhere. It follows that

$$
\begin{aligned}
E_{u v} & =E\left[\cos \left(\phi(t)+\psi_{u}\right) \cos \left(\phi(t)+\psi_{v}\right)\right] \\
& =\int_{-\infty}^{+\infty} \cos \left(x+\psi_{u}\right) \cos \left(x+\psi_{v}\right) f(x) d x \\
& =\frac{1}{2 \pi} \int_{0}^{2 \pi} \cos \left(x+\psi_{u}\right) \cos \left(x+\psi_{v}\right) d x .
\end{aligned}
$$

Using trigonometric identities and some simplifications, one can verify that

$$
E_{u v}=\frac{1}{2} \cos \left(\psi_{u}-\psi_{v}\right) .
$$

Therefore, it follows that

$$
E\left[i_{u}(t) i_{v}(t)\right]=\left(\frac{E\left[a^{2}(t)\right]}{2}\right) \cos \left(\psi_{u}-\psi_{v}\right) .
$$

Finally, one gets

$$
\mathbf{R}_{i}=\frac{E\left[a^{2}(t)\right]}{2}\left[\begin{array}{ccc}
1 & -\frac{1}{2} & -\frac{1}{2} \\
-\frac{1}{2} & 1 & -\frac{1}{2} \\
-\frac{1}{2} & -\frac{1}{2} & 1
\end{array}\right] .
$$

One can also verify that

$$
\beta_{i}^{2}=\operatorname{trace}\left[\mathbf{R}_{i}\right] / 3=E\left[a^{2}(t)\right] / 2 .
$$

\footnotetext{
${ }^{5}$ The formal proof can be derived from (42) and (43).
} 
Using these equations and the definition of the Concordia matrix in (7), one can verify that

$$
\mathbf{R}_{i}=\frac{3}{2} \beta_{i}^{2} \mathbf{C}^{\mathrm{T}} \mathbf{C} .
$$

Next, using an eigenvalue decomposition, $\mathbf{R}_{i}$ can also be decomposed as

$$
\mathbf{R}_{i}=\mathbf{U} \Lambda \mathbf{U}^{\mathrm{T}}
$$

where $\mathbf{U}$ is a $3 \times 2$ orthogonal matrix $\left(\mathbf{U}^{\mathrm{T}} \mathbf{U}=\mathbf{I}_{2}\right)$ containing the two eigenvectors and $\Lambda=\operatorname{diag}\left(\lambda_{1}, \lambda_{2}\right)$ is a diagonal matrix containing the two nonzero associated eigenvalues $\lambda_{1}$ and $\lambda_{2}$.

By identifying (38) and (39), one gets

$$
\begin{aligned}
\mathbf{U} & =(\mathbf{W C})^{\mathrm{T}} \\
\Lambda & =\frac{3 \beta_{i}^{2}}{2} \mathbf{I}_{2}
\end{aligned}
$$

where $\mathbf{W}$ is a $2 \times 2$ orthogonal matrix, i.e., $\mathbf{W}^{\mathrm{T}} \mathbf{W}=$ $\mathbf{W} \mathbf{W}^{\mathrm{T}}=\mathbf{I}_{2}$. This orthogonal matrix comes from the fact that the eigenvalue decomposition is not unique.

Using (40) in (13), one gets

$$
\begin{aligned}
\mathbf{y}^{(p)}(t) & =\beta_{i} \Lambda^{-\frac{1}{2}} \mathbf{U}^{\mathrm{T}} \mathbf{i}(t) \\
& =\mathbf{W}\left(\sqrt{\frac{2}{3}} \mathbf{C i}(t)\right)=\mathbf{W} \mathbf{y}^{(c)}(t) .
\end{aligned}
$$

As $\mathbf{W}$ is a $2 \times 2$ orthogonal matrix, $\mathbf{W}=\left\{\mathbf{W}_{1}(\theta), \mathbf{W}_{2}(\theta)\right\}$, where $\theta \in \mathbb{R}$ and

$$
\begin{aligned}
& \mathbf{W}_{1}(\theta)=\left[\begin{array}{cc}
\cos (\theta) & -\sin (\theta) \\
\sin (\theta) & \cos (\theta)
\end{array}\right] \\
& \mathbf{W}_{2}(\theta)=\left[\begin{array}{cc}
\cos (\theta) & \sin (\theta) \\
\sin (\theta) & -\cos (\theta)
\end{array}\right] .
\end{aligned}
$$

As $\mathbf{y}^{(c)}(t)=[a(t) \cos (\phi(t)), a(t) \sin (\phi(t))]^{\mathrm{T}}$, it can be shown, using trigonometric identities, that

$$
\begin{aligned}
& \mathbf{W}_{1}(\theta) \mathbf{y}^{(c)}(t)=\left[\begin{array}{l}
a(t) \cos (\phi(t)+\theta) \\
a(t) \sin (\phi(t)+\theta)
\end{array}\right] \\
& \mathbf{W}_{2}(\theta) \mathbf{y}^{(c)}(t)=\left[\begin{array}{l}
a(t) \cos (\phi(t)-\theta) \\
a(t) \sin (\phi(t)-\theta)
\end{array}\right] .
\end{aligned}
$$

Therefore, without loss of generality, the PCA components can be expressed as

$$
\begin{aligned}
& y_{2}^{(p)}(t)=a(t) \cos (\phi(t)-\theta) \\
& y_{1}^{(p)}(t)=a(t) \sin (\phi(t)-\theta) .
\end{aligned}
$$

Let us consider an unbalanced system whose components are given by $\mathbf{s}(t)=\mathbf{D i}(t)$. Using an eigenvalue decomposition, the covariance matrix, denoted $\mathbf{R}_{s}=E\left[\mathbf{s}(t) \mathbf{s}^{\mathrm{T}}(t)\right]$, can be decomposed as

$$
\mathbf{R}_{s}=E\left[\mathbf{s}(t) \mathbf{s}^{\mathrm{T}}(t)\right]=\mathbf{U}_{d} \Lambda_{d} \mathbf{U}_{d}^{\mathrm{T}}
$$

where $\mathbf{U}_{d}$ is a $3 \times 2$ orthogonal matrix and $\Lambda_{d}$ is a $2 \times 2$ diagonal matrix. Using (5) and (39), $\mathbf{R}_{s}$ can also be expressed as

$$
\begin{aligned}
\mathbf{R}_{s} & =\mathbf{D} \mathbf{R}_{i} \mathbf{D} \\
& =\mathbf{D U} \Lambda \mathbf{U}^{\mathrm{T}} \mathbf{D}
\end{aligned}
$$

where $\mathbf{R}_{i}=\mathbf{U} \Lambda \mathbf{U}^{\mathrm{T}}$ is the covariance matrix for a balanced system. By identifying (45) and (46), one gets

$$
\mathbf{U}_{d} \Lambda_{d}^{\frac{1}{2}}=\mathbf{D U} \Lambda^{\frac{1}{2}} \mathbf{V}^{\mathrm{T}}
$$

where $\mathbf{V}$ is a $2 \times 2$ orthogonal matrix. This matrix comes from the fact that the equality $\mathbf{U}_{d} \Lambda_{d} \mathbf{U}_{d}^{\mathrm{T}}=\mathbf{D} \mathbf{U} \Lambda \mathbf{U}^{\mathrm{T}} \mathbf{D}$ is satisfied for any orthogonal matrix $\mathbf{V}$. Taking the inverse of the previous equation leads to

$$
\Lambda_{d}^{-\frac{1}{2}} \mathbf{U}_{d}^{\mathrm{T}}=\mathbf{V} \Lambda^{-\frac{1}{2}} \mathbf{U}^{\mathrm{T}} \mathbf{D}^{-1} .
$$

Using these equations and (13), the PCA components of the unbalanced system, denoted $\mathbf{g}_{d}(t)$, can be expressed

$$
\begin{aligned}
\mathbf{y}^{(p)}(t) & =\beta_{s} \Lambda_{d}^{-\frac{1}{2}} \mathbf{U}_{d}^{\mathrm{T}} \mathbf{s}(t) \\
& =\beta_{s} \mathbf{V} \Lambda^{-\frac{1}{2}} \mathbf{U}^{\mathrm{T}}\left(\mathbf{D}^{-1} \mathbf{s}(t)\right) \\
& =\mathbf{V}\left(\beta_{s} \Lambda^{-\frac{1}{2}} \mathbf{U}^{\mathrm{T}} \mathbf{i}(t)\right) .
\end{aligned}
$$

Let us express $\beta_{s}$ with respect to $\beta_{i}$. By using (5), (35), and the normalization assumption $\left(\sum_{k=1}^{3} \alpha_{k}^{2}=3\right)$, one gets

$$
\begin{aligned}
\beta_{s} & =\operatorname{trace}\left[\mathbf{R}_{s}\right] / 3 \\
& =\sum_{k=1}^{3} \frac{\alpha_{k}^{2} E\left[i_{k}^{2}(t)\right]}{3} \\
& =\frac{E\left[a^{2}(t)\right]}{2}\left(\frac{1}{3} \sum_{k=1}^{3} \alpha_{k}^{2}\right)=\beta_{i} .
\end{aligned}
$$

By using (41), (51), and (52), one can conclude that

$$
\mathbf{y}^{(p)}(t)=\mathbf{V}\left(\beta_{i} \Lambda^{-\frac{1}{2}} \mathbf{U}^{\mathrm{T}} \mathbf{i}(t)\right)=\mathbf{V} \mathbf{W} \mathbf{y}^{(c)}(t) .
$$

As $\mathbf{V}$ and $\mathbf{W}$ are orthogonal matrices, it follows that $\mathbf{V W}$ is also an orthogonal matrix. Therefore, $\mathbf{y}^{(p)}(t)$ can be expressed as

$$
\mathbf{y}^{(p)}(t)=\mathbf{W}_{d} \mathbf{y}^{(c)}(t)
$$

where $\mathbf{W}_{d}=\mathbf{V W}$ is a $2 \times 2$ orthogonal matrix. As (54) is similar to (41), a similar development as in this Appendix leads to

$$
\begin{aligned}
& y_{2}^{(p)}(t)=a(t) \cos (\phi(t)-\theta) \\
& y_{1}^{(p)}(t)=a(t) \sin (\phi(t)-\theta) .
\end{aligned}
$$

Let us consider the AM signal in (1). Let us also assume that the random variable $x=2 \pi f_{a} t(\bmod 2 \pi)$ is distributed in $[02 \pi[$ according to a uniform pdf, i.e., $f(x)=1 / 2 \pi$ if $x \in[0,2 \pi[$ and $f(x)=0$ is elsewhere. Under this assumption, one gets

$$
\begin{aligned}
\mu_{a} & =E[a(t)] \\
& =\int_{0}^{2 \pi} \alpha\left(1+m_{a} \cos (x)\right) f(x) d x \\
& =\alpha .
\end{aligned}
$$

Therefore, it follows that

$$
\sigma_{a}^{2}=E\left[\left(a(t)-\mu_{a}\right)^{2}\right]=\mu_{a}^{2} m_{a}^{2} E\left[\cos ^{2}(x)\right] .
$$

Using (32) and (34), one gets $E\left[\cos ^{2}(x)\right]=1 / 2$. It follows that

$$
\sigma_{a}^{2}=\frac{\mu_{a}^{2} m_{a}^{2}}{2} .
$$




\section{REFERENCES}

[1] M. Benbouzid and G. Kliman, "What stator current processing based technique to use for induction motor rotor faults diagnosis?," IEEE Trans. Energy Convers., vol. 18, no. 2, pp. 238-244, Jun. 2003.

[2] A. Garcia-Perez, R. de Jesus Romero-Troncoso, E. Cabal-Yepez, and R. Osornio-Rios, "The application of high-resolution spectral analysis for identifying multiple combined faults in induction motors," IEEE Trans. Ind. Electron., vol. 58, no. 5, pp. 2002-2010, May 2011.

[3] J. Cusido, L. Romeral, J. Ortega, J. Rosero, and A. Espinosa, "Fault detection in induction machines using power spectral density in wavelet decomposition," IEEE Trans. Ind. Electron., vol. 55, no. 2, pp. 633-643, Feb. 2008.

[4] M. Blodt, P. Granjon, B. Raison, and G. Rostaing, "Models for bearing damage detection in induction motors using stator monitoring," IEEE Trans. Ind. Electron., vol. 55, no. 4, pp. 1813-1822, Apr. 2008.

[5] M. Blodt, J. Regnier, and J. Faucher, "Distinguishing load torque oscillations and eccentricity faults in induction motors using stator current Wigner distributions," IEEE Trans. Ind. Appl., vol. 45, no. 6, pp. 19912000, Nov./Dec. 2009

[6] J. Antonino-Daviu, M. Riera-Guasp, M. Pineda-Sanchez, and R. Pérez, "A critical comparison between DWT and Hilbert-Huang-based methods for the diagnosis of rotor bar failures in induction machines," IEEE Trans. Ind. Appl., vol. 45, no. 5, pp. 1794-1803, Sep./Oct. 2009.

[7] H. Douglas, P. Pillay, and A. Ziarani, "A new algorithm for transient motor current signature analysis using wavelet," IEEE Trans. Ind. Appl., vol. 40, no. 5, pp. 1361-1368, Sep./Oct. 2004.

[8] M. Riera-Guasp, J. Antonio-Daviu, J. Roger-Folch, and M. P. M. Palomares, "The use of the wavelet approximation signal as a tool for the diagnosis of rotor bar failure," IEEE Trans. Ind. Appl., vol. 44, no. 3, pp. 716-726, May/Jun. 2008.

[9] S. Kia, H. Henao, and G. Capolino, "Diagnosis of broken-bar fault in induction machines using discrete wavelet transform without slip estimation," IEEE Trans. Ind. Appl., vol.45, no. 4, pp. 1395-1404, Jul./Aug. 2009.

[10] J. Pons-Llinares, J. Antonino-Daviu, M. Riera-Guasp, M. PinedaSanchez, and V. Climente-Alarcon, "Induction motor diagnosis based on a transient current analytic wavelet transform via frequency b-splines," IEEE Trans. Ind. Electron., vol. 58, no. 5, pp. 1530-1544, May 2011.

[11] M. Pineda-Sanchez, M. Riera-Guasp, J. Roger-Folch, J. Antonino-Daviu, J. Perez-Cruz, and R. Puche-Panadero, "Diagnosis of induction motor faults in time-varying conditions using the polynomial-phase transform of the current," IEEE Trans. Ind. Electron., vol. 58, no. 4, pp. 1428-1439, Apr. 2011.

[12] A. Gandhi, T. Corrigan, and L. Parsa, "Recent advances in modeling and online detection of stator interturn faults in electrical motors," IEEE Trans. Ind. Electron., vol. 58, no. 5, pp. 1564-1575, May 2011.

[13] M. Blodt, M. Chabert, J. Regnier, and J. Faucher, "Mechanical load fault detection in induction motors by stator current time-frequency analysis," IEEE Trans. Ind. Appl., vol. 42, no. 6, pp. 1454-1463, Nov./Dec. 2006.

[14] I. Jaksch and P. Fuchs, "Rotor cage faults detection in induction motors by motor current demodulation analysis," in Proc. SDEMPED, Cracow, Poland, 2005, pp. 247-252.

[15] M. Blodt, D. Bonacci, J. Regnier, M. Chabert, and J. Faucher, "On-line monitoring of mechanical faults in variable-speed induction motor drives using the Wigner distribution," IEEE Trans. Ind. Electron., vol. 55, no. 2, pp. 522-533, Feb. 2008.

[16] S. Kia, H. Henao, and G. Capolino, "Analytical and experimental study of gearbox mechanical effect on the induction machine stator current signature," IEEE Trans. Ind. Appl., vol. 45, no. 4, pp. 1405-1415, Jul./Aug. 2009.

[17] M. Nemec, K. Drobnic, D. Nedeljkovic, R. Fiser, and V. Ambrozic, "Detection of broken bars in induction motor through the analysis of supply voltage modulation," IEEE Trans. Ind. Electron., vol. 57, no. 8, pp. 28792888, Aug. 2010.

[18] A. Oppenheim, R. Schafer, and W. Padgett, Discrete-Time Signal Processing, 3rd ed. Englewood Cliffs, NJ: Prentice-Hall, 2009.

[19] P. Maragos, J. Kaiser, and T. Quatieri, "Energy separation in signal modulations with application to speech analysis," IEEE Trans. Signal Process., vol. 41, no. 10, pp. 3024-3051, Oct. 1993.

[20] A. Mohanty and C. Kar, "Fault detection in a multistage gearbox by demodulation of motor current waveform," IEEE Trans. Ind. Electron., vol. 53, no. 4, pp. 1285-1297, Jun. 2006.

[21] I. Jaksch, "Fault diagnosis of three-phase induction motors using envelope analysis," in Proc. SDEMPED, Atlanta, GA, 2003, pp. 289-293.

[22] I. Jaksch and J. Bazant, "Demodulation methods for exact induction motor rotor fault diagnosis," in Proc. SDEMPED, Vienna, Austria, 2005, pp. 1-5.

[23] A. D. Silva, R. Povinelli, and N. Demerdash, "Induction machine broken bar and stator short-circuit fault diagnostics based on three-phase stator current envelopes," IEEE Trans. Ind. Electron., vol. 55, no. 3, pp. 13101318, Mar. 2008.

[24] I. Jaksch and P. Fuchs, "Demodulation analysis for exact rotor faults detection under changing parameters," in Proc. SDEMPED, Cargese, France, 2009, pp. 1-7.

[25] A. Stefani, A. Bellini, and F. Filippetti, "Diagnosis of induction machines' rotor faults in time-varying conditions," IEEE Trans. Ind. Electron., vol. 56, no. 11, pp. 4548-4556, Nov. 2009.

[26] R. Puche-Panadero, M. Pineda-Sanchez, M. Riera-Guasp, J. Roger-Folch, E. Hurtado-Perez, and J. Perez-Cruz, "Improved resolution of the MCSA method via Hilbert transform, enabling the diagnosis of rotor asymmetries at very low slip," IEEE Trans. Energy Convers., vol. 24, no. 1, pp. 52-59, Mar. 2009.

[27] Y. Amirat, V. Choqueuse, and M. Benbouzid, "Condition monitoring of wind turbines based on amplitude modulation," in Proc. IEEE ECCE, Atlanta, GA, 2010, pp. 2417-2421.

[28] B. Trajin, M. Chabert, J. Regnier, and J. Faucher, "Hilbert versus Concordia transform for three phase machine stator current time-frequency monitoring," Mech. Syst. Signal Process., vol. 23, no. 8, pp. 2648-2657, Nov. 2009.

[29] A. Cardoso and S. Saraiva, "Computer-aided detection of airgap eccentricity in operating three-phase induction motors by Park's vector approach," IEEE Trans. Ind. Appl., vol. 28, no. 5, pp. 897-901, Sep./Oct. 1993.

[30] A. Cardoso, S. Cruz, and D. Fonseca, "Inter-turn stator winding fault diagnosis in three-phase induction motors, by Park's vector approach," IEEE Trans. Energy Convers., vol. 14, no. 3, pp. 595-598, Sep. 1999.

[31] H. Nejjari and M. Benbouzid, "Monitoring and diagnosis of induction motors electrical faults using a current Park's vector pattern learning approach," IEEE Trans. Ind. Appl., vol. 36, no. 3, pp. 730-735, May/Jun. 2000.

[32] S. Cruz and A. M. Cardoso, "Stator winding fault diagnosis in threephase synchronous and asynchronous motors, by the extended Park's vector approach," IEEE Trans. Ind. Appl., vol. 37, no. 5, pp. 1227-1233, Sep./Oct. 2001.

[33] F. Zidani, M. Benbouzid, D. Diallo, and M. Naït-Saïd, "Induction motor stator faults diagnosis by a current Concordia pattern-based fuzzy decision system," IEEE Trans. Energy Convers., vol. 18, no. 4, pp. 469-475, Dec. 2003.

[34] D. Diallo, M. Benbouzid, D. Hamad, and X. Pierre, "Fault detection and diagnosis in an induction machine drive: A pattern recognition approach based on Concordia stator mean current vector," IEEE Trans. Energy Convers., vol. 20, no. 3, pp. 512-519, Sep. 2005.

[35] J. Park, D. Lee, and M. Chun, "Fault diagnosis for induction machines using kernel principal component analysis," in Proc. ISNN-Advance in Neural Networks, 2006, vol. 3973, pp. 406-413.

[36] I. Onel and M. Benbouzid, "Induction motor bearing failure detection and diagnosis: Park and Concordia transform approaches comparative study," IEEE/ASME Trans. Mechatronics, vol. 13, no. 2, pp. 257-262, Apr. 2008.

[37] S. Das, P. Purkait, and S. Chakravorti, "Space-vector characterization of induction motor operating conditions," in Proc. 15th Nat. Power Syst. Conf., Bombay, India, 2008, pp. 512-517.

[38] H. Razik, M. Beltrao, and E. Roberto, "A novel monitoring of load level and broken bar fault severity applied to squirrel-cage induction motors using a genetic algorithm," IEEE Trans. Ind. Electron., vol. 56, no. 11, pp. 4615-4626, Nov. 2009.

[39] V. N. Ghate and S. V. Dudul, "Cascade neural-network-based fault classifier for three-phase induction motor," IEEE Trans. Ind. Electron., vol. 58, no. 5, pp. 1555-1563, May 2011.

[40] J. Martins, V. F. Pires, and A. Pires, "Unsupervised neural-networks-based algorithm for on-line diagnosis of three-phase induction motor stator fault," IEEE Trans. Ind. Electron., vol. 54, no. 1, pp. 259-264, Feb. 2007.

[41] V. Pires, J. Martin, and A. Pires, "Eigenvector/eigenvalue analysis of a 3D current referential fault detection and diagnosis of an induction motor," Energy Convers. Manage., vol. 51, no. 5, pp. 901-907, May 2010.

[42] J. Proakis, Digital Communications. New York: McGraw-Hill, 2001.

[43] S. Kay, Fundamentals of Statistical Signal Processing: Estimation Theory. Upper Saddle River, NJ: Prentice-Hall, 1993, ser. Prentice-Hall signal processing series.

[44] A. Walker, "On the estimation of a harmonic component in a time series with stationary independent residuals," Biometrika, vol. 58, no. 1, pp. 2136, 1971.

[45] D. Rife and R. Boorstyn, "Single-tone parameter estimation from discrete observations," IEEE Trans. Inf. Theory, vol. IT-20, no. 5, pp. 591-598, Sep. 1974.

[46] T. Anderson, An Introduction to Multivariate Statistical Analysis. Hoboken, NJ: Wiley, 1984.

[47] A. Hyvarinen, J. Karunen, and E. Oja, Independent Component Analysis. Hoboken, NJ: Wiley, 2001. 


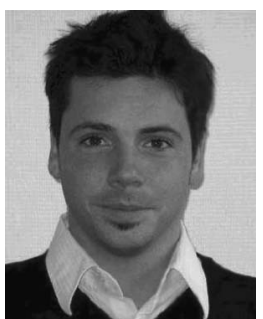

Vincent Choqueuse (S'08-M'09) was born in Brest, France, in 1981. He received the Dipl.-Ing. and M.Sc. degrees from the University of Technology of Troyes, Troyes, France, in 2004 and 2005, respectively, and the Ph.D. degree from the University of Brest, Brest, in 2008.

Since September 2009, he has been an Associate Professor with the Institut Universitaire de Technologie de Brest, University of Brest, and a Member of the Brest Laboratory of Mechanics and Systems (LBMS) (EA 4325). His research interests focus on signal processing and statistics for diagnosis and multiple-input multiple-output systems.

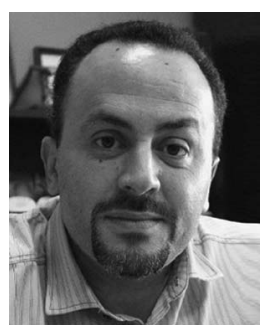

Mohamed El Hachemi Benbouzid (S'92-M'95SM'98) was born in Batna, Algeria, in 1968. He received the B.Sc. degree in electrical engineering from the University of Batna, Batna, in 1990, the M.Sc. and Ph.D. degrees in electrical and computer engineering from the National Polytechnic Institute of Grenoble, Grenoble, France, in 1991 and 1994, respectively, and the Habilitation à Diriger des Recherches degree from the University of Picardie "Jules Verne," Amiens, France, in 2000.

After receiving the Ph.D. degree, he joined the Professional Institute of Amiens, University of Picardie "Jules Verne," where he was an Associate Professor of electrical and computer engineering. Since September 2004, he has been with the Institut Universitaire de Technologie de Brest, University of Brest, Brest, France, where he is a Professor of electrical engineering. His main research interests and experience include the analysis, design, and control of electric machines, variable-speed drives for traction, propulsion, and renewable energy applications, and fault diagnosis of electric machines.

Dr. Benbouzid is a Senior Member of the IEEE Power Engineering, IEEE Industrial Electronics, IEEE Industry Applications, IEEE Power Electronics, and IEEE Vehicular Technology Societies. He is an Associate Editor of the IEEE TRANSACTIONS ON ENERGY CONVERSION, the IEEE TRANSACTIONS ON INDUSTRIAL ELECTRONICS, the IEEE TRANSACTIONS ON VEHICULAR TECHNOLOGY, and the IEEE/ASME TRANSACTIONS ON MECHATRONICS.

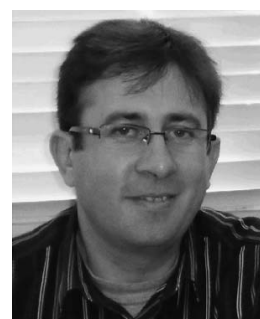

electronics
Yassine Amirat was born in Annaba, Algeria, in 1970. He received the B.Sc. and M.Sc. degrees in electrical engineering from the University of Annaba, Annaba, in 1994 and 1997, respectively. $\mathrm{He}$ is currently working toward the Ph.D. degree in wind turbine condition monitoring at the University of Brest, Brest, France.

$\mathrm{He}$ is currently a Lecturer with the Institut $\mathrm{Su}$ perieur de l'Electronique et du Numérique, Brest. His current research interests are the condition monitoring and the control of electrical drives and power

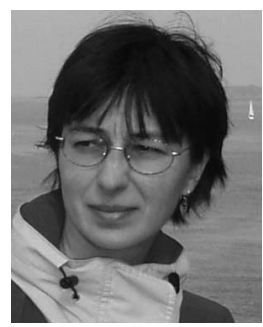

Sylvie Turri was born in France in 1972. She received the M.Sc. degree in electrical engineering from the University of Nancy, Nancy, France, in 1996 and the Ph.D. degree in electrical engineering from the University of Franche-Comté, Belfort, France, in 2000

After receiving the Ph.D. degree, she joined the Systèmes et Applications des Technologies de l'Information et de l'énergie Laboratory (UMR CNRS 8029), Ecole Normale Supérieure de Cachan, Cachan, France, as a Teaching and Research Associate. In 2004, she joined the Institut Universitaire de Technologie de AixMarseille, University of Marseille III, Marseille, France, as an Associate Professor of electrical engineering. She was appointed to the Laboratoires des Sciences de l'Information et des Systémes Laboratory (UMR CNRS 6168). In 2006, she joined the Institut Universitaire de Technologie de Brest, University of Brest, Brest, France, as an Associate Professor of electrical engineering and a Member of the Brest Laboratory of Mechanics and Systems (LBMS) (EA 4325). Her main research interests are in the field of electromechanical systems (power generation and fault diagnosis). 